\section{Cave: Katze an Bord!}

\author{
Über den Wolken muss die Allergenfreiheit wohl \\ grenzenlos sein, könnte man vermuten. Dass dem nicht \\ unbedingt so ist, zeigt der folgende Erlebnisbericht einer \\ Leserin des Allergo Journal.
}

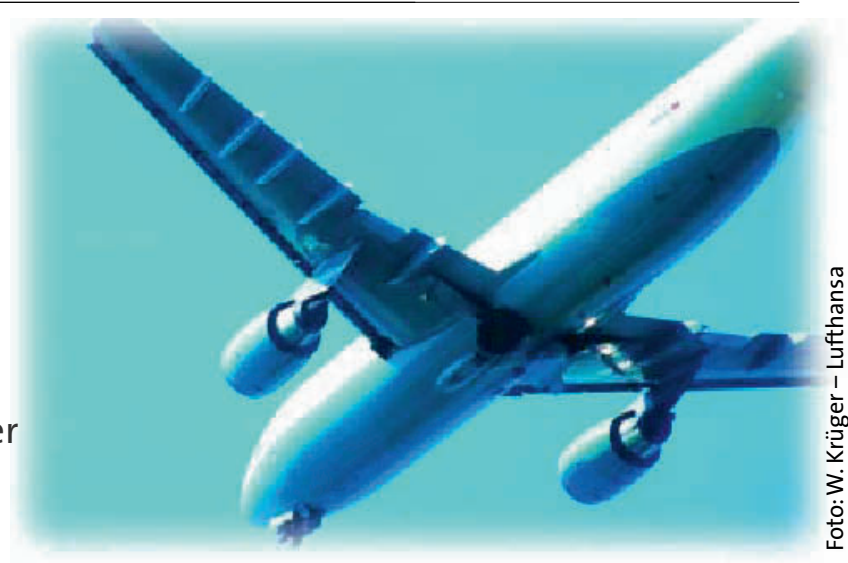

A m 15. September 2002 befand ich mich auf dem Flug LH 3917 von Neapel nach München und war eingecheckt auf Platz 26A. Voller Entsetzen musste ich sehen, dass zwei Katzen selbstverständlich in luftdurchlässigen Transportkästen - zunächst wie Koffer eingecheckt wurden, sich jedoch anschließend im Passagierraum befanden. Die katzenhaltende Familie war zusätzlich in Reihe 26 und 27 direkt neben mir eingeteilt.

Ich bin hochgradig katzenhaarallergisch, hatte aber glücklicherweise meine Medikamente im Handgepäck, so dass ich lebensbedrohliche Beschwerden im Flugzeug verhindern konnte. Durch das freundliche Verständnis der Stewardess erhielt ich außerdem einen Platz in der 11. Reihe und konnte somit wenigstens entfernt von den Katzen sitzen.

Als Betroffene mit Katzenhaarallergie möchte ich darauf hinweisen, dass es durchaus passieren könnte, dass ein allergischer Fluggast seine Notfallmedikamente im Koffer eingecheckt und somit in der Kabine nicht zur Hand hat. Ein schwerer Asthmaanfall und weitere Komplikationen könnten die Folge sein.

Dr. Gabriele Heilgemeir

Fachärztin für Dermatologie

Augsburger Straße 18

86368 Gersthofen

\section{Stellungnahme}

$\mathrm{W}$ ir bedauern die geschilderte Situation sehr. Glücklicherweise hatte die Passagierin die notwenige Medizin griffbereit und unsere Flugbegleiter konnten sie an Bord umsetzen.

Mit dem Thema Allergien hat sich Lufthansa schon seit geraumer Zeit aus- einandergesetzt, so werden unsere Flugbegleiter in ihrer Ausbildung dahingehend geschult. Außerdem halten wir an Bord dementsprechende Medikamente bereit.

Das Flugzeug ist heutzutage ein Massentransportmittel wie z. B. auch Busse und Bahnen. Allein Lufthansa befördert jährlich ca. 45 Millionen Passagiere. Die geschilderte Situation kann überall eintreten, deshalb obliegt es den Betroffenen, Vorsorge zu treffen und die entsprechenden Medikamente stets bei sich zu führen. Eine Allergie gehört somit zum allgemeinen Lebensrisiko der betroffenen Personen.

In der Regel werden Haustiere bei Lufthansa in einem temperaturkontrollierten und mit Druckausgleich versehenen Frachtabteil befördert. Unsere Passagiere können ihre Haustiere auf dem gleichen Flug befördern lassen und - wie bei vielen anderen internationalen Flug-
In der Regel werden Tiere abgeschottet von den Passagieren im Bauch von Verkehrsflugzeugen transportiert - Ausnahmen sind allerdings möglich.

gesellschaften auch - in begrenzter Zahl und unter bestimmten Voraussetzungen auch in der Passagierkabine, wie im vorliegenden Fall. Der Transport erfolgte nach den von der IATA (der Dachorganisation der internationalen Linienfluggesellschaften) aufgestellten Regeln, deshalb muss der Transportbehälter auch offen sein.

Wir hoffen, Ihnen einige Hintergrundinformationen zum Thema Tierbeförderung gegeben zu haben.

\section{Alfred Kluge}

Deutsche Lufthansa AG

Passageverkaufsleitung Süd

Lenbachplatz 1

80333 München

\section{Was ist dran am Lactobacillus?}

\author{
Nur wenige Maßnahmen zur Prävention atopischer Erkrankungen \\ bei Neugeborenen sind unumstritten. Dazu gehören das Stillen des \\ Kindes und der Rauchverzicht der Mutter. Ein Leser des Allergo \\ Journal möchte wissen, wie die aktuelle Datenlage zur Gabe von \\ Probiotika aussieht.
}

W as ist wirklich dran an der Einnahme von Lactobacillus GG bei schwangeren atopischen Müttern? Das Unternehmen Infectopharm behauptet, die Entwicklung einer Atopie beim Ungeborenen bzw. Neugeborenen abstoppt und wirbt mit Doppelblindstudass die Einnahme von Lactobacillus dien im Lancet. Kann man der Sache Glauben schenken? Ich bitte um Informationen.

\section{Dr. Klaus Hübner}

Facharzt für Dermatologie

Kasinostraße 17

52066 Aachen 